$\begin{array}{r}\text { Volume and Issues Obtainable at Center for Sustainability Research and Consultancy } \\ \text { Journal of Business and Social Review in Emerging Economies } \\ \text { ISSN: 2519-089X (E): 2519-0326 } \\ \text { Volume 6: No. 4, December } 2020 \\ \text { JSRᄃ } \\ \text { Journal homepage: www.publishing.globalcsrc.org/jbsee } \\ \hline\end{array}$

\title{
Violent Behavioral Outcomes: An Empirical Examination of Perceived Parenting Rejection Practices in Lahore, Pakistan
}

\author{
${ }^{1}$ Hassan Raza, ${ }^{2}$ Saif-ur-Rehman Saif Abbasi, ${ }^{3}$ Nazneen Habib \\ ${ }^{1 \& 2}$ Department of Sociology, International Islamic University, Islamabad, Pakistan, \\ raza.hassan04@gmail.com \\ ${ }^{3}$ Department of Sociology, University of Azad Jammu \& Kashmir, Muzaffarabad, Pakistan
}

\begin{tabular}{l}
\hline ARTICLE DETAILS \\
\hline History \\
Revised format: November \\
2020 Available Online: December \\
2020 \\
\hline Keywords \\
Parenting Practices, \\
Parental Rejection, Violent \\
Behaviour. \\
\hline
\end{tabular}

JEL Classification

M10, M12

\section{OPEN ACCESS}

ABSTRACT

Across the cultures, parenting or child-rearing practices are considered as the concrete behaviors towards the developmental process of rearing or socialization of the children. The study splits the conception of parenting practices among two domains as parental acceptance and parental rejection, depending on the behavioural outcomes under investigation. The cross sectional research was conducted on young males attending colleges in Lahore, Pakistan to understand that how parental rejection dimensions of parenting manifest the violent behavioral outcome among male college students. The research within the Pakistani indigenous culture on parenting practices and its inter-relationship between youth violent behavioural outcomes provide stems from the theoretical anchorage in the socio-psychological works. The sample of 816 male students from public colleges of Lahore was included to collect the responses through self-administered questionnaire as a tool of the study. The results indicated that measures of perceived parental rejection accounts variations in the violent behavioural outcomes of the young male students for $26.2 \%(\mathrm{R} 2=0.262)$. The study suggests that positive parenting interventions may cause to reduce the risk factors (i.e. violent behavioral practices) among youth.

(C) 2020 Center for Sustainability Research and Consultancy Pakistan under a Creative Commons Attribution-NonCommercial-ShareAlike 4.0

Corresponding author's email address: raza.hassan04@gmail.com

Recommended citation: Raza, H., Abbas, S. R. S. \& Habib, N. (2020). Violent Behavioural Outcomes: An Empirical Examination of Perceived Parenting Rejection Practices in. Journal of Business and Social Review in Emerging Economies, 6(4), 1463-1467

\section{Introduction}

Researchers highlighted the significance of the inter-relationship between perceived parenting rejection practices and behavioural outcomes among children (Peterson \& Hann, 1999). However, the debate on the adaptive and maladaptive parenting practices for one's cultural context has been linked to operationalize the conceptions (Barnhart et al., 2013). For instance, the researchers argued the linkages between harsh/strict parenting (i.e. maladaptive in Europe and America) and maladaptive behavioural outcomes among the children (Maccoby \& Martin, 1983), while association of such parenting practices with risk behavior in Asian families (Leung et al., 1998; Rudy \& Grusec, 2006). 
Researchers in the family studies have recognized that parenting practices are expected to contribute in the process of developmental behavioural outcomes among children (Peterson \& Hann, 1999; Kotchick $\&$ Forehand, 2002). Parents, as major agents in the process of socialization, have been considerably significant to rear or socialize their children to adapt with the prevalent and acceptable values and normative practices in the society (Aneshensel, 2005). Scholars have studied parenting practices with violent behavioural outcome extensively (Campaert, Annalaura, \& Menesini, 2018; Manzoni \& Schwarzenegger, 2018; Acar, Uçuş, \& Yıldız, 2017; Knerr, Gardner, and Cluver, 2013; Gilbert et al., 2009; Howells \& Rosenbaum, 2007; Gershoff, 2002; Chang et al., 2003; Pianta \& Harbers, 1996). Neverthless, the study explores the uncovered or neglected aspect of parenting dimensions especially within the reference of South Asian heritage and Pakistani cultural context.

Across the countries, the studies have highlighted numerous factors that lead to the prevalence of violent behavioural outcomes among youth members in the society. For instance, the study conducted in six countries has significantly associated parental mal-practices in the child-rearing process and violence as the behavioural outcome among children (Manzoni \& Schwarzenegger, 2018; Howells \& Rosenbaum, 2007; Durant et al., 1999). The researchers have also documented the use of physical punishment or harsh parenting practices could become more consistent predictor of violent behavioural outcomes among children especially young males (Acar, Uçuş, and Y1ldız, 2017; Pianta \& Harbers, 1996; Loeber et al., 1990).

The current study attempts to see the linkages of parental rejection measures (i.e. -ve reinforcements) and the violent behavioral outcomes among young male students. However, it has been very keenly observed within the Pakistani cultural context that parents right after the matriculation level of education (i.e. $10^{\text {th }}$ grade students) of their children lose their monitoring and control as compared to school level. This developmental stage could arise questions on the parental creditability for the rearing process of their children. This study is particularly designed to address those questions which linked violent behavioural outcomes of the male youth members and parenting rejection practices measures.

\section{Methodology}

The study was conducted on the sample of 816 male students at public sector colleges of Lahore with 97\% C.I and 3\% margin of error for the calculation of sample. The study used a standardized Parental Acceptance and Rejection Questionnaire (PARQ) as a tool after validation in the local context. The list of boy's public colleges was collected by the office of Director Colleges, Lahore. The students at intermediate level of education through filled out the questionnaire with standard instructions written on it, administered in the class timings by their teachers. Moreover, the reliabilities of the scales used were reported as high cronbach scores i.e. greater than 0.70 in all scales.

\section{Results}

Table 1: Demographics of male students at public sector colleges of Lahore, Pakistan

\begin{tabular}{lc}
\hline Variable & $\mathrm{N}(\%)$ \\
\hline Study year at college (Higher Secondary) & $451(55 \%)$ \\
$1^{\text {st }}$ year & $365(45 \%)$ \\
$2^{\text {nd }}$ year & $502(62 \%)$ \\
Residential pattern & $314(38 \%)$ \\
$\quad$ Urban & $368(45 \%)$ \\
$\quad$ Rural & $448(55 \%)$ \\
Family System & \\
$\quad$ Nuclear Family & $323(40 \%)$ \\
Joint Family & $310(38 \%)$ \\
Monthly Family Income (in Pak. Rupees) & $113(14 \%)$ \\
$\quad$ Up to 20,000 & \\
20,001 to 40,000 & \\
40,001 to 60,000 & \\
Above 60,000 & $70(8 \%)$ \\
\hline
\end{tabular}


Table 1 depicts the demographics of male students at public sector colleges of Lahore, Pakistan. There were more than half of the respondents $(451,55 \%)$ who got them enrolled in the $1^{\text {st }}$ year of higher secondary school level and slightly less than half of the respondents $(365,45 \%)$ were enrolled in $2^{\text {nd }}$ year at higher secondary school. The significant majority $(502,62 \%)$ of the respondents who belong to urban residential pattern and little less than two fifth of the respondents $(314,38 \%)$ were living in the rural areas at the time of enrollment at public sector colleges of Lahore. In addition, there were 368 $(45 \%)$ of the students were from nuclear family system and 448 (55\%) were extended or joint family system. The results illustrates that more than three fourth of the sample consists within the monthly family income group having Rs. 40000 or less income. However, there was very minute sampled population having more than Rs. 60000 income.

Table No. 2: Relationship between -ve parental Rejection practices and violent behavioural outcomes among male students in public sector colleges

\begin{tabular}{ll}
\hline & Violent Behaviour \\
\cline { 2 - 2 } Hostility/Aggression & $0.459 * *$ \\
Indifference Neglect & $0.470 * *$ \\
Undifferentiated Rejection & $0.457 * *$ \\
\hline
\end{tabular}

\section{Correlation significant at $0.01 *$}

Table 2 showed the relationship between parental rejection measures with the violent behavioural outcomes among male students. The findings illustrate positive and significant relationship among perceived hostility/aggression parenting practices and violent behavioural outcomes among young males at public sector colleges of Lahore $(\mathrm{r}=0.459, \mathrm{p}<0.01)$. Moreover, there was a statistically significant relationship between perceived indifference neglect practices for child-rearing and violent behavioral outcomes among male students $(\mathrm{r}=-0.0 .470, \mathrm{p}<0.01)$. In addition, the positive and statistically significant correlation was reported among perceived undifferentiated parenting rejection practices and violent behavioural outcomes among male students $(\mathrm{t}=0.457 \mathrm{p}<0.01)$.

\section{Main Effect Model}

To see the effect of parental rejection measures on the violent behavioural outcomes among make students of public sector colleges of Lahore, simple linear regression was applied to observe the variations among the variables. The results indicated that parenting rejection measures, altogether accounts for $26.2 \%\left(\mathrm{R}^{2}=0.262\right)$ variations in the violent behavioural outcomes of young males at public sector colleges. However, beta $(\beta)$ values among the three measures of parenting rejection practices were statistically significant with violent behavioural outcomes.

Table 3: Effect of Parental Rejection measures on the violent behavioral outcome among students

\begin{tabular}{lll}
\hline Variables & Beta (Standardized) & Sig. Value \\
\hline Hostility/Aggression & 0.459 & $0.001^{* * *}$ \\
Indifference Neglect & 0.470 & $0.001^{* * *}$ \\
Undifferentiated Rejection & 0.457 & $0.007 * *$ \\
F-Value & 8.322 & \\
$\mathrm{R}^{2}$ & 0.262 & \\
Adjusted $\mathrm{R}^{2}$ & 0.260 & \\
\hline
\end{tabular}

Note $* * *=p<.001, * *=p<.01$

\section{Discussion \& Conclusion}

The present study examines the effect of parenting rejection practices on the youth violent behavioural outcomes among male students in Lahore, Pakistan. Major study hypothesis of the study states the 
parenting rejection measures contributed towards the violent behavioural outcomes among young male students in public sector college of Lahore. The study splits into three measures of parenting rejection practices (i.e. hostile, indifference neglect, and rejection practices), as they are considered to be more significant dimensions for the development of violent behaviors among young one's especially emerging adults (Grusec 2011; Patterson 2002).

The results of the study reported that there is a significant effect of parenting rejection measures on violent behavioural outcomes among male youth students. The current study supports the notion that children learn violent behavior from their parents while disengaging them morally by the result of poor parenting practices such as aggressive, neglecting, and rejected parenting practices. Whenever children experience harsh disciplinary parenting practices, they may learn to believe that victims can be punished for their own misconducts and wrong doings. The study also supported the view of linkages between poor parenting practices and moral disengagements among young or adolescents, where harsh discipline or parental rejection/neglect may socialize children with more likely to appear moral disengagements among them and resultantly aggressive or violent behaviors emerge due to these engagements (Maas, Herrenkohl, \& Sousa, 2008).

The findings of the current research depict that parenting rejection measures accounts for $26.2 \%$ variations for the developmental outcomes of violent behavior. There is a significant and consistent need to improve the parenting interventions which may diminish the risk factors in developing violent behavioural outcomes. However, the interventions may particularly be enhanced within the domain of parental awareness (knowledge), parental attitudes, and parent-child interactions for better outcomes. Furthermore, more rigorous parenting programs in terms of contextualization, especially within problem families, at the local and national level to prevent the risk behavioural outcomes which could be more effective, acceptable and feasible to strengthen the family structures. Nevertheless, the process that links parenting rejection and violent behavior among youth and how other mediators and moderators become relevant for studying needs to be better understood for developing the violent or aggressive behaviours among young or adolescents.

\section{References}

Acar, I. H., Uçuş, Ş., \& Yıldız, S. (2019). Parenting and Turkish children's behaviour problems: the moderating role of qualities of parent-child relationship. Early Child Development and Care, 189(7), 1072-1085.

Barnhart, C. M., Raval, V. V., Jansari, A., \& Raval, P. H. (2013). Perceptions of parenting style among college students in India and the United States. Journal of Child and Family Studies, 22(5), 684-693.

Campaert, K., Nocentini, A., \& Menesini, E. (2018). The role of poor parenting and parental approval for children's moral disengagement. Journal of Child and Family Studies, 27(8), 2656-2667.

Chang, L., Schwartz, D., Dodge, K. A., \& McBride-Chang, C. (2003). Harsh parenting in relation child emotion regulation and aggression. Journal of family psychology, 17(4), 598.

DuRant, R. H., Smith, J. A., Kreiter, S. R., \& Krowchuk, D. P. (1999). The relationship between early age of onset of initial substance use and engaging in multiple health risk behaviors among young adolescents. Archives of pediatrics \& adolescent medicine, 153(3), 286-291.

Gershoff, E. T. (2002). Corporal punishment by parents and associated child behaviors and experiences: a metaanalytic and theoretical review. Psychological Bulletin, 28(4), 539 579.

Gilbert, R., Widom, S. C., Browne, K., Fergusson, D., Webb, E., \& Janson, J. (2009). Burden and consequences of child maltreatment in high-income countries. The Lancet, 373(9657), 68-81

Grusec, J. E. (2011). Socialization processes in the family: social and emotional development. Annual Review of Psychology, 62, 243-69. 
Howells, N. L., \& Rosenbaum, A. (2007). Effects of perpetrator and victim gender on negative outcomes of family violence. Journal of Family Violence, 23(3), 203-209.

Knerr, W., Gardner, F., \& Cluver, L. (2013). Improving positive parenting skills and reducing harsh and abusive parenting in low-and middle-income countries: A systematic review. Prevention science, 14(4), 352-363.

Kotchick, B. A., \& Forehand, R. (2002). Putting parenting in perspective: A discussion of the contextual factors that shape parenting practices.Journal of child and family studies, 11(3), 255-269.

Leung, K., Lau, S., \& Lam, W. L. (1998). Parenting styles and academic achievement: A cross cultural study. Merrill-Palmer Quarterly (1982-), 157-172.

Loeber, R., Brinthaupt, V. P., \& Green, S. M. (1990). Attention deficits, impulsivity, and hyperactivity with and without conduct problems: Relationships to delinquency and unique contextual factors. In R. J. McMahon \& R. DeV. Peters (Eds.), Behavior disorders of adolescence: Research, intervention, and policy in clinical school settings (pp. 39-62). New York: Plenum.

Maas, C., Herrenkohl, T. I., \& Sousa, C. (2008). Review of research on child maltreatment and violence in youth. Trauma, Violence, \& Abuse, 9(1), 56-67.

Maccoby, E. E., \& Martin, J. A. (1983). Socialization in the context of the family: Parent child interaction. Handbook of child psychology: formerly Carmichael's Manual of child psychology/Paul H. Mussen, editor.

Manzoni, P., \& Schwarzenegger, C. (2019). The influence of earlier parental violence on juvenile delinquency: The role of social bonds, self-control, delinquent peer association and moral values as mediators. European Journal on Criminal Policy and Research, 25(3), 225-239.

Patterson, G. R. (2002). The early development of coercive family process. In J. B. Reid, G. R. Patterson \& J. Snyder (Eds.), Antisocial behavior in children and adolescents: A developmental analysis and model for intervention (pp. 25-44). Washington, DC: American Psychological Association.

Peterson, G. W., \& Hann, D. (1999). Socializing children and parents in families. In Handbook of marriage and the family (pp. 327-370). Springer US.

Pianta, R. C., \& Harbers, K. L. (1996). Observing mother and child behavior in a problem solving situation at school entry: Relations with academic achievement. Journal of School Psychology, 34, 307-322.

Rudy, D., \& Grusec, J. E. (2006). Authoritarian parenting in individualist and collectivist groups: Associations with maternal emotion and cognition and children's self esteem. Journal of Family Psychology, 20(1), 68. 